\title{
POLÍTICAS PÚBLICAS ENQUANTO CONSEQUÊNCIA DOS DIREITOS CONSTITUCIONAIS
}

\author{
PUBLIC POLICIES AS A CONSEQUENCE \\ OF CONSTITUTIONAL RIGHTS \\ Pedro Miguel Alves Ribeiro Correia ${ }^{1}$ \\ Arcênio Pereira Santos Filho ${ }^{2}$
}

I

Doutoramento em Ciências Sociais (Especialidade em Administração Pública), Universidade Técnica de Lisboa (UTL). Licenciatura em Estatística de Gestão de Informação, Universidade Nova de Lisboa (NOVA).

Professor no Instituto Superior de Ciências Sociais e Políticas (ISCSP), Universidade de Lisboa (ULisboa). Vice-Presidente e Investigador Integrado do Centro de Administração e Políticas Públicas (CAPP), ISCSP-ULisboa. Investigador Colaborador do Centro Interdisciplinar de Estudos de Género (CIEG), ISCSPULisboa. Colaborador Estrangeiro do Grupo de Pesquisa em Administração da Justiça, Universidade de Brasília. Coordenador do Observatório Nacional de Administração Pública (ONAP), ISCSP-ULisboa. Consultor para a Área de Planeamento e Política Legislativa da DireçãoGeral da Política de Justiça (DGPJ) do Ministério da Justiça de Portugal 2

Doutorando em Administração Pública, Instituto Superior de Ciências Sociais e Políticas, Universiade de Lisboa
RESUMO: Este trabalho trata do tema das políticas públicas, levando em conta o princípio nomeado no artigo 1, inciso III da Constituição Federal do Brasil de 1988 - o princípio da dignidade da pessoa humana - e, do artigo 5, os direitos e garantias fundamentais. Dois tópicos são desenvolvidos: o referente à administração pública, e sua relação com o Direito administrativo, e o que diz respeito à gestão do Estado. Duas políticas públicas são exemplos: O Plano das Olimpíadas 2016 da Prefeitura do Rio de Janeiro e o Bolsa família. Definese política pública recorrendo-se ao seu histórico, à produção crítica e a dois dicionários do tema.

palavras-chave: Políticas Públicas; Administração Pública; Gestão Pública.

ABSTRACT: This paper deals with the theme of public policies, taking into account the principle named in article 1, subsection III of the Federal Constitution of Brazil of 1988 - the principle of the dignity of the human person - and of article 5, the fundamental rights and guarantees. Two topics are developed: the one related to the public administration, and its relation with the Administrative Law, and what concerns the management of the State. Two public policies are examples: The 2016 Olympics Plan of the Rio de Janeiro City Hall and the Bolsa Familia. Public policy is defined based on its history, critical production and two dictionaries of the theme.

KEYwORds: Public Policies; Public Administration; Public Management. 


\section{INTRODUÇÃO}

Este trabalho tem o objetivo de contextualizar a principal e indissolúvel função das Políticas Públicas no Brasil, considerando o princípio nomeado no artigo 1, inciso III da Constituição Federal do Brasil de 1988 - o princípio da dignidade da pessoa humana - e, do artigo 5, os direitos e garantias fundamentais, observando as políticas públicas decorrentes da atuação administrativa e de gestão do Estado. A Administração Pública é o topo, figurativamente, de uma pirâmide que se constitui da ação institucional do Executivo, do Legislativo e do Judiciário. Na base dessa pirâmide está a Gestão Pública que cuida das necessidades da sociedade civil por meio de programas sociais.

Os programas que, em seu conjunto são denominados políticas públicas, dependem da ação do Poder Legislativo, que, por sua vez, recorrer ao Direito Administrativo que fornece os princípios jurídicos para garantir os direitos civis. Com a determinação de pôr em destaque a dinâmica dos três poderes - o que executa por função da Lei, o que legisla e o Judiciário -, para apontar o tema das políticas interessadas no bem-estar social, é necessário destacar a importância do Direito Administrativo cuja função é ser o principal agente de regulação da Administração Pública, lembrar que a administração direta dispõe de órgãos públicos de natureza federal, estadual ou municipal responsáveis imediatos pelas atividades administrativas do Estado.

Logo a seguir, o objeto, que deu margem ao estudo do que é denominado Políticas Públicas, começa a ser tratado com a ênfase no fato serem meios condutores de programas que envolvem a administração de benefícios para a sociedade civil. Não falta o exemplo de Associações que emergem para atender a uma necessidade de um determinado grupo social, assim como a alusão ao Plano das Olimpíadas 2016 no Rio de Janeiro cuja administração municipal cuidou da necessidade de criar benefícios em matéria de mobilidade urbana, a fim de contemplar não só os competidores, mas também pensando um legado para o cidadão da cidade do Rio de Janeiro que sediou o referido evento de projeção e tradição mundial.

A referência ao Plano das Olimpíadas 2016 da Prefeitura do Rio de Janeiro serve como exemplo de como se dá a gestão pública em tal matéria de política pública cujo conceito transmite uma complexidade que, historicamente, deu margem ao entendimento de ser um objeto de estudo por ter se constituído em discurso ou prática disciplinar ou saber.

\section{HERMENÊUTICA de POLÍTICAS PÚBLICAS}

Dando desenvolvimento ao tema deste trabalho, convém tomar o seu objeto - políticas públicas - no sentido dado por seu contexto: administração de benefícios e garantias para a sociedade civil, sem deixar de lado os poderes constituídos por uma nação democrática, e sem deixar de levar em conta a da sociedade, cada vez maior e cada vez mais ati- 
va, nas questões de interesses pessoais e do coletivo, que se reflete na criação de associações, sindicatos ou qualquer outro órgão representativo do coletivo. Para dar uma ideia da importância dessas associações, é relevante lembrar a origem da Fundação de Desenvolvimento da Pesquisa - uma entidade de direito privado sem fins lucrativos reconhecida como Fundação de apoio pelos Ministérios da Educação e da Ciência, Tecnologia e Inovação, criada em 1975 por um grupo de professores da Universidade Federal de Minas Gerais para ser instrumento de apoio às atividades acadêmicas e de pesquisa e, desde então, vem contribuindo para o seu desenvolvimento nas diversas áreas do conhecimento.

Pois bem, há um Dicionário de Políticas Públicas da Universidade de Minas Gerais com cento e noventa e sete verbetes, elaborado por cento e oitenta professores, principalmente da área das ciências sociais, gestores públicos, estudantes das mais variadas áreas, das diversas universidades de todo País, cada um com uma abordagem científica sobre os assuntos. A importância desse Dicionário aqui lembrado é fazer reflexões sobre os sentidos que as políticas públicas no Brasil vêm tomando, considerando as diversas áreas do saber das Ciências. Os colaboradores tomam o conceito veiculado pelo verbete políticas públicas de acordo com área de seus conhecimentos. O usuário desse Dicionário percebe a complexidade de uma função que cabe ao Governo que é não só criar programas sociais para fazer valer garantias ao cidadão, mas também, por exemplo, dar assistência legal à criança e ao adolescente por meio de um Estatuto como é o caso do Estatuto da Criança e do Adolescente (Lei no 8. 069, 13 de julho de 1990).

\section{O VERBETE POLÍTICAS PÚBLICAS}

A leitura do verbete "políticas públicas" no Dicionário de Políticas Públicas (2012) ${ }^{3}$ permite observar um campo de conhecimento mobilizado para definir e contextualizar a administração das políticas públicas no Brasil já considerando a ação obrigatória do Estado brasileiro de observar direitos e garantias fundamentais para a sociedade civil como institui o Artigo 5 da Constituição Federal do Brasil de 1988 que trata dos direitos e garantias fundamentais.

O título II - Dos direitos e garantias fundamentais do Capítulo I, Art. $5^{\mathrm{o}}$ - Dos direitos e deveres individuais e coletivos - inaugura na Constituição brasileira os direitos chamados de direitos de primeira geração. Esta classificação veio com o constitucionalismo liberal que surgiu com a Revolução Francesa e a Independência dos Estados Unidos.

As políticas públicas são estabelecidas entre o Estado e a sociedade. O processo da inserção e da trajetória das Políticas Públicas dirige-se para Gestão Pública como alicerce para realização dos Direitos constitucionais. Assim, o termo gestão, que na sua origem latina significa ação de gerir, refere-se também à gerência, administração, direção de negócios, ao ato de administrar negócios ou bens alheios sem 
Nascente, $1967,2^{0}$

Tomo, D-I, p.425.

Ibidem, p.424

Di Giovanni, G.; Nogueira M. A. Dicionário de políticas públicas( 2015). 2 ed. São Paulo: Unesp/Fundap. autorização do proprietário ${ }^{4}$ (Nascente, 1967). O verbo gerir do qual o substantivo em questão se deriva, no seu sentido referencial, ganhou o registro de "tornar produtivo pelo desenvolvimento"5 (Nascente, 1967). Na esfera institucional, a gestão pública implica um ciclo que começa na sociedade civil e é filtrado pelo Estado, através das políticas públicas, e retorna à sociedade na forma de Direitos e Obrigações. Essa expressão pode sugerir simplicidade e facilidade no desiderato que pressupõe. $\mathrm{Na}$ realidade, porém, a gestão pública traduz uma complexa responsabilidade, uma vez que o rumo das atividades que devem ser executadas, segundo determinação de políticas públicas, depende do destinatário da ação, isto é, do grupo social que será por elas beneficiado.

O verbete em pauta é tratado logo de saída como "decisões de ordem pública e como "estratégias de atuação pública", sem deixar de lado a ação relevante do Governo do Estado. A crítica ao verbete que se deve fazer é não só por pecar pela falta de fundamentação de ordem jurídica, mas também pela não recorrência ao processo quase natural da constituição de um discurso ou disciplina que se tornou objeto de conhecimento.

No Dicionário de políticas públicas $(2015)^{6}$, as políticas públicas, como objeto estudo, são apresentadas por um amplo mapeamento histórico e conceitual. Logo na sua Introdução, seus organizadores - Geraldo di Giovanni, que é professor do Instituto de Economia e pesquisador do Núcleo de Estudos de Políticas Públicas da Unicamp, e Aurélio Nogueira, professor titular de Teoria Política e diretor do Instituto de Políticas Públicas e Relações Internacionais da Unesp, revelam, de certa forma, o critério da seleção dos verbetes. O conceito de políticas públicas é associado ao Estado voltado para o bem-estar social. Segundo Marco Aurélio Nogueira, o conceito de política pública decorre da vontade de direitos individuais e sociais.

A luta pelos direitos sociais, na Europa no pós-guerra, repercutiu, no Brasil, no período de retomada da democracia, na elaboração da Constituição de 1988. A necessidade de redemocratização e de conquista da cidadania uniu direitos e políticas públicas.

O Artigo $5^{\circ}$ incluído sob o título II - "Dos Direitos e Garantias Fundamentais" - na Constituição Federal Brasileira (1988) - , é apresentado em capítulos. Logo no capítulo I estão os direitos individuais: “Todos são iguais perante a lei, sem distinção de qualquer natureza, garantindo-se aos brasileiros e aos estrangeiros residentes no País a inviolabilidade do direito à vida, à liberdade, à igualdade, à segurança e à propriedade [...]. Talvez não seja exagero depreender disto que os programas de políticas públicas decorrem das garantias já previstas pelos Estados democráticos que fazem de suas Constituições a referência maior da Lei dos direitos humanos: direito à vida, à liberdade, à igualdade, à segurança e à propriedade, mas fica faltando observar em que circunstâncias os Governos democráticos lançam mão de planos de políticas públicas. De certa forma, este trabalho, neste ponto, pauta-se no aspecto decisório dos Governos democráticos na ação de 

(2015). Dicionário de políticas públicas. 2 ed. São Paulo:

Unesp - Fundap, pp 275-276. programas para garantir os direitos individuais e coletivo. As garantias que procedem dos Governos democráticos já são decorrentes do Estado entendido como uma instituição política com poder de decisão em momentos em que a sociedade civil apresenta uma certa demanda, o que ganha visibilidade na atuação do Estado como organizador de programas de políticas públicas para atender demandas sociais.

Com o raciocínio que conjuga a política do Estado e as pretensões da sociedade civil, evidenciam-se os agenciamentos da sociedade civil que vão implicar a produção de políticas públicas como a mediação política de Governos democráticos. A sociedade, portanto, concebida para ser governada no âmbito do Estado burocratizado e de repartições, tornou-se objeto das políticas públicas. No Brasil atual a plataforma de políticas públicas tornou-se moeda para a vitória nas urnas.

Os cinco princípios fundamentais da República Federativa do Brasil estão relacionados, na Constituição 1988, no título I: Dos Princípios Fundamentais no Artigo 1: "A República Federativa do Brasil, formada pela união indissolúvel dos Estados e Municípios e do Distrito Federal, constitui-se em Estado Democrático de Direito e tem como fundamentos: “ I - a soberania; II - a cidadania III - a dignidade da pessoa humana; IV - os valores sociais do trabalho e da livre iniciativa; V - o pluralismo político" .

O segundo - da cidadania - e o III - da dignidade da pessoa humana são princípios constitucionais que dão margem a associar a legitimidade das políticas públicas produzidas pelo Estado democrático de Direito com os direitos humanos concebidos como conjunto de faculdades, prerrogativas e procedimentos que materializam exigências éticas de comportamento relativas à dignidade da pessoa humana. A doutrina dos direitos humanos (XVII e XVIII) foi uma reação aos governos arbitrários. Foram as seguintes: a Bill of Rights inglesa (1689), as Declarações de Direitos dos Estados da Virgínia, Pensilvânia e Maryland (1776), a Constituição Americana de 1787 (e suas nove primeiras emendas) e a Declaração Francesa dos Direitos do Homem e do cidadão de 1789 .

Em sua primeira fase, a doutrina dos direitos humanos pôs freio ao poder do Estado moderno nacional, mas os séculos seguintes, XIX e XX, novos direitos civis, políticos, econômicos, sociais e culturais foram acrescentados. A relevância desses novos direitos está no fato de ser exigido do Estado a prestação de serviços que lhes dizem respeito?. O artigo 6 da Constituição brasileira de 1988 cuida dessa prestação de serviços dando atendimento às obrigações já de segunda geração.

A complexidade inerente à Administração Pública se dá por conta de sua base utilitária. Por exemplo, durante o reinado do rei Hammurabi da Babilónia (2123 - 2081 a.C.), atual Iraque, foi elaborado um código único que continha 282 leis que abarcavam as normas de execução de negócios, do comportamento pessoal, das relações interpessoais, dos salários, das punições e muitos outros aspetos da vida em sociedade (Gonçalves e Lira, 2009; Wren, 1994). Este é, provavelmente, 
Morin, E. (2003). Introdução ao pensamento complexo $(4$ ed., pp. 25-97). (E. Lisboa, Trad.). São Paulo: Sulina. o precursor de todas as constituições e leis públicas escritas na história da Humanidade (Jreisat,1997). Fica absolutamente claro que a Política Pública é o radical da Administração Pública, como da Gestão Pública, desde sempre. Uma das abordagens analíticas mais frequentes relativamente à Administração Pública corresponde a um ponto de vista predominantemente sociopolítico e refere-se ao enfoque histórico-estrutural que lança o seu olhar, principalmente, sobre os atores que podem participar do processo de formulação de políticas como o Estado, os indivíduos ou grupos, as organizações e os setores da sociedade no desempenho de funções de natureza económica e política. Estes, de acordo com o momento histórico em que se inserem, e em relação ao jogo de forças resultantes, conseguem influenciar, em maior ou menor grau, no processo de formulação de políticas públicas.

Uma outra abordagem diz respeito ao enfoque administrativo organizacional e refere-se à preocupação com a organização da Administração Pública em si, isto é, o seu funcionamento interno e a relação que estabelece com o contexto em que está imersa e com o qual interage. Cabe ressaltar que estas abordagens têm vindo a ser reinterpretadas à luz do paradigma da complexidade.

Uma melhor compreensão da visão do mundo implica encará-lo como um sistema complexo. Esta visão leva em consideração as teorias da complexidade como um prelúdio necessário à compreensão das teorias de sistemas.

Todavia, o que é a complexidade? Segundo Morin ${ }^{8}$ (2003), à primeira vista, o complexo é um tecido; complexo é tudo aquilo que é tecido em conjunto, constituído por elementos heterogéneos inseparavelmente associados, representando o paradoxo do uno e do múltiplo. O termo complexidade tem sido utilizado pela ciência contemporânea para dar ressonância e relevância a alguns conceitos, mas apresenta limitações, ou, se preferirmos, coloca fronteiras, quando, efetivamente, o que se pretende é pôr em marcha uma forma de estudar o tecido da realidade com todos os elementos que a compõem.

A complexidade está associada a várias teorias, como a sistémica, a cibernética e a teoria da informação. O desenvolvimento destas teorias permite compreender conceitos como emergência, acaso, acontecimento, interações e relações, entre outros.

A complexidade não está orientada por uma visão reducionista e mecanicista do mundo. O panorama da complexidade está sujeito a indeterminações, incertezas, fenômenos aleatórios e ao acaso.

No trânsito fugaz do ser humano pela sua existência, um dos fatores mais marcantes diz respeito à complexidade. Para Morin (2003), os modos de organização que regem a atuação das pessoas resultam das interações sociais que podem acontecer por via de afinidades, contradições, dominações ou comunicações, entre outros, e que conduzem ao aparecimento das tensões entre ordem e desordem. Estas interações devem ser entendidas numa perspectiva complexa porque estão inseridas nas organizações como produto do exercício do poder. Assim 
Lei $\mathrm{n}^{-0} 10.836$, de $9 / 1 / 2004$ e Decreto nº 5/209,de17/9/2004 10

Medida Provisória $\mathrm{n}^{\mathrm{o}} \mathrm{132}$, de 20 de outubro de 2003 sendo, Morin (2003) traz à baila o conceito de cultura organizacional na qual se vão tecendo redes de poder.

Pensar de modo complexo significa configurar um pensamento multidimensional que permita entender que as estruturas hierárquicas não são as únicas detentoras de poder nas organizações. As redes formadas pelas interações entre os seus membros e com agentes externos podem, num dado momento, transformar o comportamento das organizações e, por conseguinte, da sua cultura.

Um exemplo prático é o Sistema de Previdência Brasileiro: um sistema vivo e complexo, permanentemente revisto e reordenado pelos seus processos, procedimentos e estratégias operacionais, como resposta às incertezas e incoerências produzidas pela suposta obrigatoriedade de recadastramento imposto aos aposentados e pensionistas.

A complexidade aborda uma mudança nos modos de administrar e gerir as organizações, pois os acontecimentos são tratados nas suas múltiplas relações vitais e não como objetos isolados.

A Administração Pública, que, no sentido amplo, é um sistema complexo, dependente do Estado, de suas normas e leis, já foi tratada tomando-se como referência as políticas públicas.

\section{A GESTÃO PÚBLICA}

De modo pragmático as atividades de caráter público, voltadas para a educação da população de um país, são oportunos exemplos da significação de Gestão Pública. Os professores, outros profissionais da educação como os assistentes sociais, psicólogos e tantos outros são os gestores legítimos nomeados pela instituição de natureza organizacional denominada Gestão Pública. Aqueles que atendem à necessidade de dar conta de programas para atender à necessidade de educar crianças e adolescentes, em idade escolar, são os gestores de ponta. O Estado é instituição representativa e de poder público para criar o conjunto de programas, portanto as políticas públicas, como meio de exercer sua legítima administração.

Os programas sociais, de um modo geral, não só atendem à população carente, como o denominado Bolsa Família9 pelo Governo do Brasil, que resultou de uma Medida Provisória ${ }^{10}$, cujo objetivo principal é fazer com que a população de jovens de família de baixa renda, em idade escolar, tenha a possibilidade de escolaridade e ser educada. Em que consiste o Bolsa Família no Brasil? Em 2001 foi criado como programa de transferência de renda condicionada federal, com a denominação de Bolsa Escola Federal. As famílias de renda per capita abaixo de noventa reais recebiam para as crianças de 6 a 15 anos um benefício no valor de quinze reais por criança. $\mathrm{O}$ que passou a ser chamado de apenas de Bolsa Família em 2003 refere-se à unificação de quatro programas sociais voltados para indivíduos de domicílios pobres pertencentes a grupos de diferentes linhas de pobreza. $\mathrm{O}$ órgão responsável por este programa é a Secretaria Nacional de Renda de Cidadania - SENARC do Ministério do Desenvolvimento Social e Combate à Fome. 
Ainda perseguindo o exemplo de um programa federal que oferece benefício à família de baixa renda e dela espera uma contrapartida, torna-se relevante entrar no procedimento burocrático: o SENARC estabelece normas de execução, define valores do benefício, define e acompanha as contrapartidas, estabelece metas, propõe o orçamento anual do Programa, define quotas por Município, faz avaliações regularmente, fixa critérios para a transferência do benefício e a sua suspensão. É, assim, órgão de responsabilidades e decisões.

Há também Programas em outras áreas que constituem a chamada política pública. No plano das Olimpíadas 2016 no Rio de Janeiro, percebe-se a administração conveniente não só do espaço urbano considerando logística e certos legados para a cidade e o cidadão, por exemplo, mas também uma política educacional. Desse fluxo materializado em edificações urbanas, por exemplo, decorre o refluxo em forma dos benefícios para formação de novos atletas e, por consequência, todo um movimento de formação de cidadania pela motivação de competir para ser premiado. Um trabalho de infraestrutura urbana da Região Portuária do Rio, incluindo transporte e serviços públicos, além da preservação das características culturais do local, é mais um fato a ser somado como ilustração da dinâmica política em matéria de gestão e administração públicas.

O Plano das Olimpíadas 2016 no Rio de Janeiro foi elaborado e conduzido pela administração municipal que cuidou da necessidade de criar benefícios em matéria de mobilidade urbana, a fim de contemplar não só os competidores, mas também pensando no legado para o cidadão. Para ilustrar o que aqui foi desenvolvido em matéria de políticas públicas, é oportuno citar o item desse Plano que se refere à requalificação urbana do entorno do Estádio Olímpico:

A reurbanização do entorno imediato do estádio e a criação da Praça do Trem constavam na Matriz de Responsabilidades, mas, por não serem obras de instalações esportivas - das quais a Matriz trata -, foram transferidas para o Plano de Políticas Públicas - Legado. Na primeira fase foram beneficiadas as ruas que formam o quadrilátero do entorno do estádio: Arquias Cordeiro, José dos Reis, Doutor Padilha e Rua das Oficinas, que ganharam novos passeios, meios-fios e sarjetas, além de implantação de infraestrutura para nova iluminação e conversão de redes aéreas para subterrâneas. As melhorias urbanísticas garantiram às calçadas acessibilidade para pessoas com deficiência. $\mathrm{O}$ entorno do estádio também ganhou uma ciclovia com $2 \mathrm{~km}$ de extensão. A Praça do Trem será uma área de lazer e vai atender a população de uma região que tem poucas opções de diversão ao ar livre. Com $35 \mathrm{mil}$ metros quadrados devolveram à cidade de tesouros arqueológicos como o antigo Cais da Imperatriz e os Jardins Suspensos do Valongo, e criaram novas opções culturais como o Museu de Arte do Rio. A previsão de inauguração do Museu do Amanhã é para o segundo semestre de 
11

Disponível em http://www. brasil2016.gov.br/pt-br
2015. As obras do Porto Maravilha estão recuperando a infraestrutura urbana da Região Portuária do Rio, incluindo transporte e serviços públicos, além da preservação das características culturais do local. O projeto revitaliza área de 5 milhões de metros quadrados, sendo $70 \mathrm{~km}$ de ruas e vias urbanizadas e a construção de 4 túneis, incluindo o maior túnel urbano rodoviário da cidade, o Túnel da Via Expressa, com $3 \mathrm{~km}$ de extensão, dentro da Via Expressa, que terá $6,8 \mathrm{~km}$. A prefeitura já entregou a Via Binário do Porto, com 3,5 km de extensão e dois túneis. ${ }^{11}$

A importância do Direito Administrativo cabe agora ser mencionada.

\section{DIREITO ADMINISTRATIVO}

O Direito Administrativo, por via de regra, antecede a Administração Pública, porque é ele o principal agente ativo regulador da Administração Pública que trata e disciplina não apenas os órgãos públicos, como pessoa jurídica, como também seus dirigentes, pessoas físicas, sejam por cargos eleitos, comissionados ou de carreira, na consecução dos interesses públicos. Segundo o jurista Leandro Cadenas, o conjunto dos princípios jurídicos que tratam da Administração Pública implica observar as entidades, órgãos, agentes públicos, ou seja, o que diz respeito ao modo pelo qual o Estado persegue o alcance de suas finalidades. Assim, tudo que diz respeito à administração pública é regido pelo Direito Administrativo.

Sob a ótica do conjunto de princípios, existe uma distinção fundamental que faz grandes diferenças entre administração direta e indireta. A característica fundamental da administração direta é a sua composição: os órgãos públicos pertencentes a ela estão ligados diretamente ao Poder executivo federal, estadual ou municipal. Esses órgãos de fato integram essas pessoas federativas denominadas: Federação, Estados e Municípios, e são responsáveis imediatos pelas atividades administrativas do Estado. Consequentemente, não possuem personalidade jurídica própria, patrimônio e autonomia administrativa, uma vez que seus orçamentos são subordinados às esferas das quais fazem parte.

Como exemplo de órgãos da administração direta pode-se citar os Ministérios do Governo Federal, as Secretarias dos Estados Federativos e dos Municípios.

Administração Indireta, por sua vez, é caracterizada por entidades que possuem personalidade jurídica própria, possuindo, portanto, patrimônio, autonomia administrativa e orçamento específico para seus fins e de responsabilidade de gestão. Os exemplos decorrentes são as Autarquias, as Fundações Públicas, Empresas Públicas e Sociedades de Economia Mista. Cada uma dessas entidades, por sua vez, possui algumas características próprias. 
LASSWELL, H. D.

(1936) Politics: who gets what, when, how. New York: American Elsevier.
Nessa linha de raciocínio aporta-se ao ordenamento jurídico, do Direito Administrativo à Administração Pública. Independentemente de conceitos subjetivos dos grandes pensadores sobre essa matéria, conclui-se que são bases fundamentais para alicerçar suas divisões de obras do Direito que atenda ao público, de um modo geral.

\section{ADMINISTRAÇÃO PÚBLICA}

Pela Constituição de 1967, a Administração Pública era meramente um setor ou uma pessoa, eleita ou não, com ou sem cargo de comissão. Não havia a matéria Ciência Administração, ou menção ao Direito Administrativo. A Seção VII - Da Fiscalização Financeiro e Orçamentária - , no artigo 72 , $\S 3$ e $\S 5$ desta Constituição é uma referência do que hoje se sabe de Administração Pública. O capítulo IV - dos Direitos e Garantias Individuais, artigo 153, § 11 - é mais uma referência.

Após onze anos da engessada burocracia constitucionalizada, para tentar conter a corrupção e desencontros dos tecnocratas, surge a Constituição de 1988 cujo capítulo VII cuida da Administração Pública como Ciência da Administração e do Direito Administrativo. O artigo 37 apresenta os princípios intrínsecos à Administração Pública, que são: legalidade, impessoalidade, moralidade, publicidade e eficiência. Com propósito de controlar as atividades administrativas da União, dos Estados, do Distrito Federal e Municípios. Assim ficou registrado no Art. 37: "A administração pública direta e indireta de qualquer dos Poderes da União, dos Estados, do Distrito Federal e dos Municípios obedecerá aos princípios da legalidade, impessoalidade, moralidade, publicidade e eficiência [...]"

\section{GESTÃO PÚBLICA E POLÍTICAS PÚBLICAS}

No contexto de políticas públicas, a Administração Pública tem seu uso indubitavelmente, referindo-se ao conjunto de entidades e órgãos que integram a administração dos três poderes: o Executivo, o Legislativo e o Judiciário das instâncias do Governo que compõem o Estado, o Distrito Federal e os Municípios.

Numa breve passagem, acerca do compromisso da Gestão Pública com as políticas públicas, verificamos que estas se foram autonomizando, quer na Europa quer nos Estados Unidos, a partir, sobretudo, de meados do século XX. Para tal contribuiu, nomeadamente, o norte-americano Lasswell ${ }^{12}$ que, em 1936, publicou a obra Politics: Who Gets What, When, How, defendendo a Ciência Política como Ciência do poder que tem por objeto a conquista e conservação do poder e pode ser entendida como um jogo de soma zero. Facilmente se percebe que Lasswell introduz na sua argumentação uma nota de ironia em relação ao Estado, quando faz as seguintes interrogações: "Quem ganha? O que se ganha? Quando se ganha? E como?". 
13

Santos, B. (2000). Para um novo senso comum: a ciência, o direito e a política na transição paradigmática (Vol.1, pp. 139-169). (Coleção Para um novo senso comum: a ciência, o direito e a política na transição paradigmática). São Paulo: Cortez.
A construção de uma área disciplinar específica, englobando a política pública, no entanto, ocorreu em meados do século passado, com a publicação de The Governmental Process (Truman, 1951) e de Policy Sciences: recent developments in scope and method (Lasswell \& Lerner 1951). O início dos estudos acerca das políticas públicas, no Brasil, deu-se um pouco mais tarde, no final dos anos setenta e princípio dos anos oitenta do século XX.

Na realidade, este novo objeto de Ciência foi ganhando expressão devido à influência do mercado capitalista de produção em países centrais cuja classe hegemónica era a burguesia e onde a concepção de modernidade estava associada ao desenvolvimento do capitalismo. Segundo Sousa Santos (2000) ${ }^{13}$, o capitalismo tornou-se um vetor de desenvolvimento que ocorreu em três períodos.

O primeiro período corresponde ao do capitalismo liberal, no século XIX; o segundo ao do capitalismo organizado, que atinge o seu ponto alto no período entre as duas guerras e nas duas primeiras décadas do pós-guerra; e o terceiro ao do capitalismo desorganizado, com início nos finais dos anos 60 do século $\mathrm{XX}$, prolongando-se até à atualidade (Sousa Santos, 2000). A caracterização destes três períodos ajuda a perceber e a demonstrar a relação que, na modernidade, se estabeleceu entre Poder jurídico e Estado liberal, em que os princípios éticos de ordem jurídica perderam espaço, e o Direito positivo potenciou e agilizou os dispositivos da regulação do mercado.

O sistema racional de leis, que emana do Estado, legitima, juridicamente, a Administração Pública. O Direito formal e racional garante a vontade do Estado pensado como agente de vontade e poder. $\mathrm{O}$ Direito moderno, de acordo com o pensamento de Weber (1992), decorre de um ato de vontade, sendo o Estado o agente dessa vontade (Sousa Santos, 2000). O Estado mínimo do constitucionalismo liberal contém em si as sementes do Estado-Providência, benevolente, do capitalismo civilizado (Sousa Santos, 2000).

Ainda de acordo com o percurso histórico traçado por Sousa Santos (2000), verifica-se que o Direito se foi gradualmente tornando estatal e científico, facto de que o Código Civil alemão de 1900 é um bom exemplo. A autonomia do Direito outorga-lhe um caráter duplo de público e privado; daqui decorre que o cidadão fica subordinado ao Estado, ao mesmo tempo que o Direito serve aos cidadãos. A distinção entre público e privado é a ilusão de que o direito privado não é um direito estatal. Mercê dos contributos do cientificismo e do estatismo, o Direito ganhou a forma utópica de regulação social, de tecnologia criada pela Ciência. Apesar de a modernidade considerar o Direito um princípio secundário de pacificação social, em relação à Ciência, ele é um artefacto científico ao serviço do Estado capitalista.

Em termos históricos, ao observarmos a relação entre o Direito, o Estado moderno e a exigência económica do capitalismo liberal, podemos concluir que há dispositivos para engendrar o que hoje se reconhece institucionalmente com o nome de Estado moderno que ajudam a 
compreender como se formalizou a Administração Pública em função da concepção de sociedade como conjunto de indivíduos empenhados em cumprir com os deveres de servir o Estado, logo submetidos ao regime jurídico desse mesmo Estado.

Como consequência do desenvolvimento capitalista, foram tomadas medidas radicais que conduziram ao pacto entre o capital e o trabalho, sob a administração do Estado; desta forma, surgiu o EstadoProvidência como possibilidade de gerir politicamente o capitalismo em países centrais. Com o Estado-Providência, emergiu, também, a obrigação política entre contribuintes e o Estado e entre beneficiários das políticas sociais e Estado.

No Brasil, o Decreto 83.740/79 de 18 de julho instituiu o Plano Nacional de Desburocratização-PND, coincidindo, sensivelmente, com o início do processo de extinção do regime militar. Foi, então, possível, retomar a reforma administrativa, dentro de uma perspectiva de descentralização, com especial ênfase no interesse do cidadão como utilizador dos serviços públicos. Pela primeira vez, o governo federal passou a tratar a questão da reforma não como uma proposição voluntarista do próprio Estado, mas como condição essencial do processo de redemocratização. Atualmente, está em vigor o Programa Nacional de Gestão e Desburocratização, regulamentado pelo Decreto 5.378/2005 de 23 de fevereiro.

A Gestão Pública não se resume a uma mera questão de eficiência e eficácia; na realidade, ela envolve, igualmente, questões de legalidade e legitimidade, a par de outros valores que transcendem os padrões restritivos dos negócios. Não se trata apenas de uma gestão interna, mas também, e antes de tudo, de uma gestão externa de um contexto sociopolítico complexo. Esta complexidade advém das intermináveis necessidades dos cidadãos de todas as classes e de todas as regiões, principalmente nos países em desenvolvimento (Kickert \& Stillmann, 1999, apud Matias-Pereira, 2012) $)^{14}$. A Constituição Federal de 1988 instituiu a descentralização e a participação como eixos centrais do processo de democratização da gestão pública brasileira, nas três esferas de governo: federal, estadual e municipal. Os Conselhos Gestores tornaram-se o novo locus de articulação política em busca da definição e formulação de políticas públicas. 


\section{CONSIDERAÇÕES FINAIS}

Neste trabalho a respeito de Políticas Públicas no Brasil dois exemplos foram dados de programas de políticas públicas no Brasil: o Bolsa Família Federal e o Plano das Olimpíadas 2016 no Rio de Janeiro. Depreende-se desses exemplos uma dinâmica entre Administração Pública e Gestão Pública, e, por consequência, as Políticas Públicas que desempenham o papel mediador e de expressão da vontade política do Governo no Brasil de fazer valer a democracia expressa pelas instituições e amparada constitucionalmente. O Direito Administrativo serve de fundamento para que a sociedade civil seja assistida em suas necessidades e carências. A Gestão Pública faz a necessidade nascer, ser materializada. $\mathrm{O}$ objetivo de fazer a leitura de um conceito - políticas públicas - aliado à noção de objeto de estudo da área da Administração Pública e com a complexidade de uma rede de atores, e de interesses, de agenciamentos governamentais e sociais - implicou a recorrência a dois exemplos de políticas sociais sob o controle governamental no Brasil bem significativas, para fugir da simplicidade definir políticas públicas no tom de um dicionário, apesar de desse instrumento não ter ficado à parte, nem ter sido desvalorizado.

Pois bem, o objetivo de articular o tema deste trabalho com os princípios fundamentais da República Federativa do Brasil regulamentados pela Constituição de 1988, defensora do Estado Democrático de Direito, se deu pela vontade de mostrar que o sentido do princípio da dignidade da pessoa humana, embora nada explicitado na letra da Carta Magna, veio da influência da Declaração dos Direitos do Homem e do Cidadão apresentada na Assembleia Nacional da França em 25 de agosto de 1789. Como falar de dignidade é muito complicado por ser um conceito de ordem moral, resta recorrer a um dos princípios do romantismo em literatura nacional. José de Alencar é uma boa referência: o índio Jaguarê do romance cujo título é Ubirajara caracteriza-se pela dignidade na pessoa que defende sua nação. A dignidade está associada à honra a ser conquistada.

Portanto, não há dúvida de ter sido o contexto em que vingou a doutrina dos direitos humanos, nos séculos XVII e XVIII, e, por consequência, a dos direitos civis e políticos, como reação aos governos arbitrários. A Constituição brasileira de pós-ditadura assimila valores morais como o da dignidade tão relevante no século XIX em que o conceito de nacionalismo se firma. 


\section{REFERÊNCIAS}

Carvalho Filho, J.S. (2000). Manual de Gestão Pública Contemporânea (3 ed.). São Paulo: Atlas.

Castro, R. B. (2006). Eficácia, Eficiência e Efetividade na Administração Pública. Associação Nacional dos Programas de Pós-Graduação em Administração-ANPAD. Anais do XXX Encontro Anual da Associação Nacional dos Programas de Pós-Graduação. Salvador: BA.

Castro, Carmem L. F.; GONTIJO, Cynthia R.B.; AMABILE, Antônio E. de N. (orgs.) (2012). Dicionário de Políticas Públicas. Barbacena: EdUEMG, 242p.

Constituição da República dos Estados Unidos do Brasil (1967). Obtido em 13 de dezembro de 2016 de: http://www.planalto. gov.br/ccivil_03/constituicao/constituicao67.htm.

Constituição da República Federativa do Brasil (1988). Obtido em 13 de dezembro de 2016 de: http://www.planalto. gov.br/ccivil_03/constituicao/constituicao.htm.

Denhardt, R. B. (2012). Teorias da Administração Pública (6 ed.). São Paulo: Cengarge Learning.

Dias, R. \& Matos, F. (2012). Políticas Públicas: princípios, propósitos e processos. São Paulo: Atlas.

Lasswell, H. D. (1936) Politics: who gets what, when, how. New York: American Elsevier.

Lasswell, H. D. (1971). Policy Sciences

New York: American Elsevier.

Matias-Pereira, J. (2012). Manual de Gestão Pública Contemporânea: análise dos efeitos das mudanças de paradigmas na administração pública brasileira (4 ed.). São Paulo: Atlas.

Morin, E. (2003). Introdução ao pensamento complexo (4 ed., pp. 25-97). (E. Lisboa, Trad.). São Paulo: Sulina. (Obra original publicada em 1985).

Santos, B. (2000). Para um novo senso comum: a ciência, o direito e a política na transição paradigmática (vol.1, pp. 139-169). (Coleção Para um novo senso comum: a ciência, o direito e a política na transição paradigmática). São Paulo: Cortez.

Weber, M. (2000). Economia e sociedade: fundamentos de uma sociologia compreensiva (4 ed., pp. 44-68). (R. Barbosa \& K. E, Barbosa, Trad.). Brasília: UNB. (Obra original publicada em 1944). 